\title{
Control and Management of Wild Hogs in Florida 1
}

William M. Giuliano and George W. Tanner²

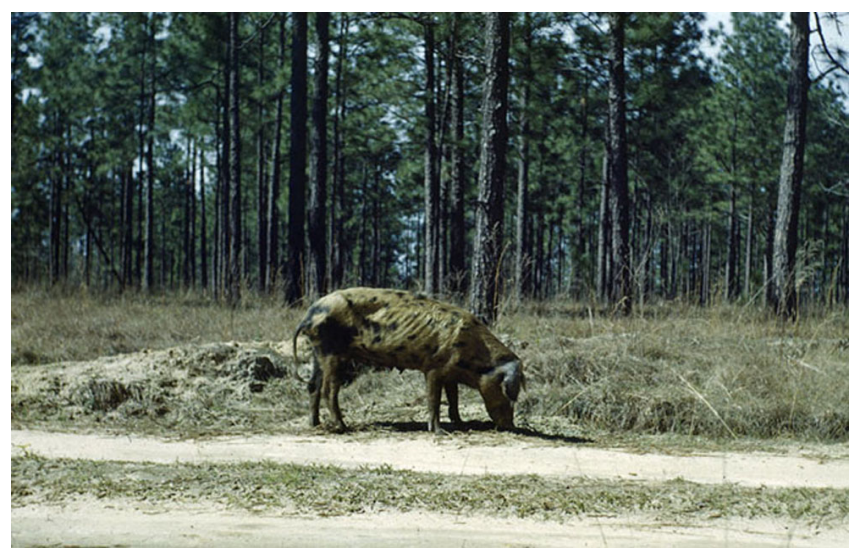

Figure 1. An exotic species in Florida, wild hogs cause significant damage but are difficult to control. Credits: National Oceanic and Atmospheric

Administration/Department of Commerce Photo.

Florida's wild hogs (Figure 1) are often referred to as feral hogs or swine and are of three general types. These include free-ranging swine that come from domesticated stock, Eurasian wild boar, and hybrids of the two. Although technically, feral refers to free-ranging animals from domesticated stock, all wild hogs are typically referred to as feral in Florida and all are considered the same species, Sus scrofa. Wild hogs are in the family Suidae (true wild pigs), none of which are native to the Americas.
Wild hogs are now found in every county in Florida and in at least 35 states and Canadian provinces, including most of the Southeast. Florida, second only to Texas, is estimated to have 500,000+ wild hogs in a relatively stable population, with 1 to 2 million in the Southeastern U.S. Some of the highest densities of hogs in Florida can be found north and west of Lake Okeechobee in areas with large forested tracts, dense understory vegetation, and limited public access. Hog numbers tend to be lower in areas with intensive agriculture and urbanization, and little water.

Additional information on the ecology of wild hogs in Florida can be found at: http://edis.ifas.ufl.edu/UW220.

\section{Problems Caused by Wild Hogs}

The opportunistic and omnivorous tendencies of wild hogs lead to many conflicts with people and wildlife. With hard mast, including acorns, as their preferred food, hogs directly compete with many popular game animals, including deer, turkeys, and squirrels (Figure 2). This competition is considered to be a significant limiting factor for populations of these native species in some areas. In addition, hogs may consume the nests and young of many reptiles (including sea turtles; Figure 3), ground-nesting

1. This document is WEC 192 and is one of a series of the Department of Wildlife Ecology and Conservation, Florida Cooperative Extension Service, Institute of Food and Agricultural Sciences (IFAS), University of Florida. First published: April 2005. Please visit the EDIS Web site at http://edis.ifas.ufl.edu for more publications.

2. William M. Giuliano is an Assistant Professor and Wildlife Extension Specialist; and George W. Tanner is a Professor; Department of Wildlife Ecology and Conservation, Cooperative Extension Service, Institute of Food and Agricultural Sciences, University of Florida, Gainesville, FL 32611.

The Institute of Food and Agricultural Sciences is an equal opportunity/affirmative action employer authorized to provide research, educational information and other services only to individuals and institutions that function without regard to race, color, sex, age, handicap, or national origin. For information on obtaining other extension publications, contact your county Cooperative Extension Service office. Florida Cooperative Extension Service/Institute of Food and Agricultural Sciences/University of Florida/Christine Taylor Waddill, Dean. 
birds, and mammals (including deer fawns). Wild hogs have also been known to consume young domestic livestock including poultry, lambs, and goats.

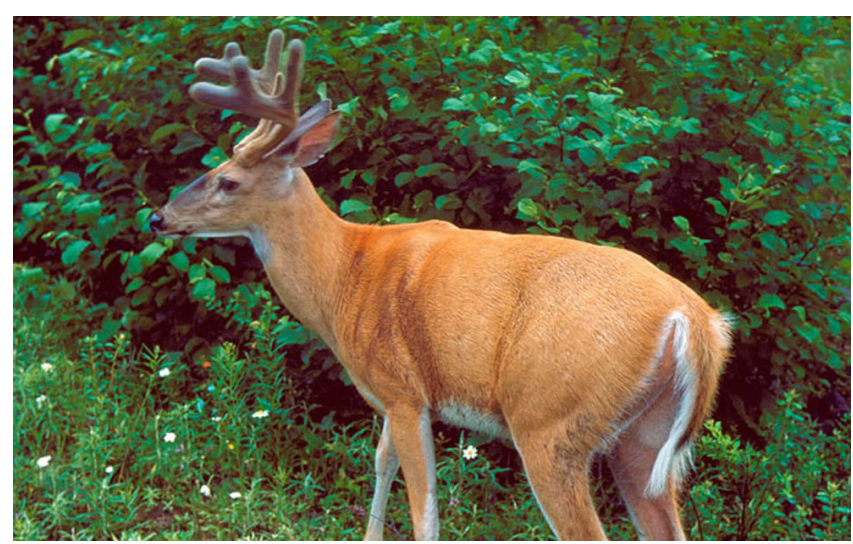

Figure 2. Wild hogs may compete with native wildlife such as white-tailed deer for food. Credits: U.S. Department of Agriculture/Photo by K.W. Gale.

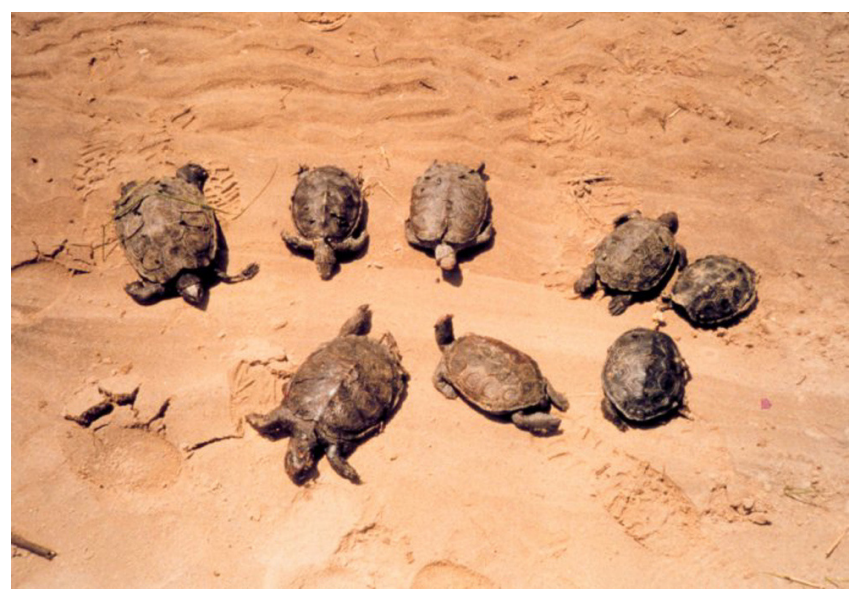

Figure 3. Hogs often prey upon the nests of ground nesting wildlife, including sea turtles, leading to significant nest losses. Credits: National Oceanic and Atmospheric Administration/Department of Commerce Photo.

When natural foods are scarce or inaccessible, hogs will readily forage on almost any agricultural crop and feed set out for livestock and wildlife, leading to significant losses. Wild hogs will also feed on tree seeds and seedlings, causing significant damage in forests, orchards, and plantations. In Florida and the Southeast, this may be a serious problem in regenerating important long-leaf pine forests (Figure 4).

Hogs rub objects, often trees, to scratch themselves. In addition, males will often "tusk" small trees, scraping off the bark with their tusks, in what is

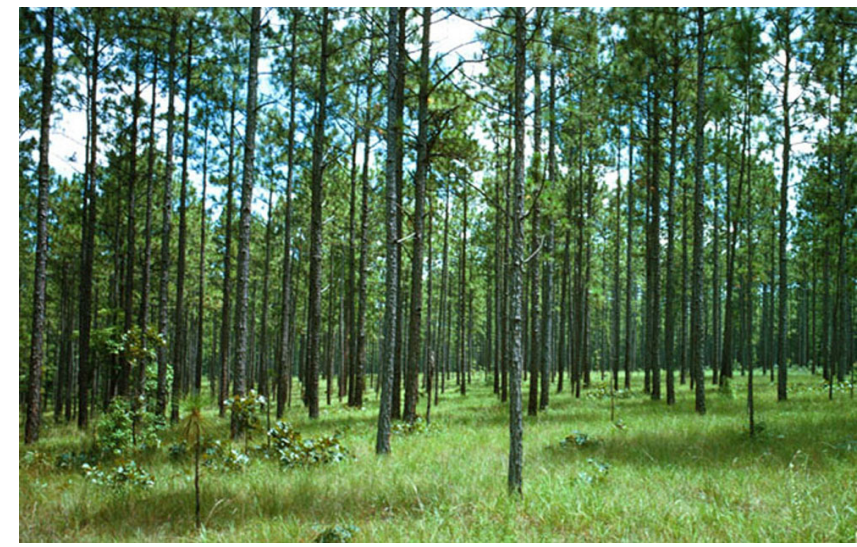

Figure 4. By eating seeds and seedlings, wild hogs can inhibit forest regeneration. Credits: U.S. Department of Agriculture/Photo by W. Boyer.

thought to be some type of dominance display. Such actions can seriously damage the rubbed objects (Figure 5).

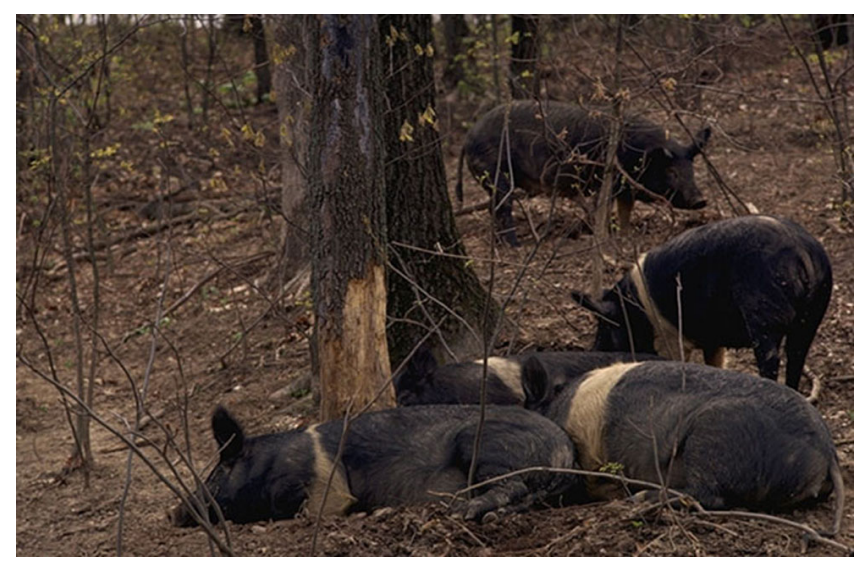

Figure 5. Rubbing and "tusking" of trees by wild hogs can cause serious damage. Credits: U.S. Department of Agriculture Photo.

In addition to the effects of consuming, knocking down, rubbing, and trampling large amounts of native vegetation and crops, the rooting behavior of hogs also causes significant damage. Rooting (digging for foods below the surface of the ground) destabilizes the soil surface, which can lead to erosion and exotic plant establishment; uproots or weakens native vegetation; and damages lawns, dikes, roads, trails, and recreation areas (Figure 6). They have also been known to damage fences and other structures.

Wallowing behavior also destroys small ponds and stream banks, and can lead to declines in water quality (Figure 7). 


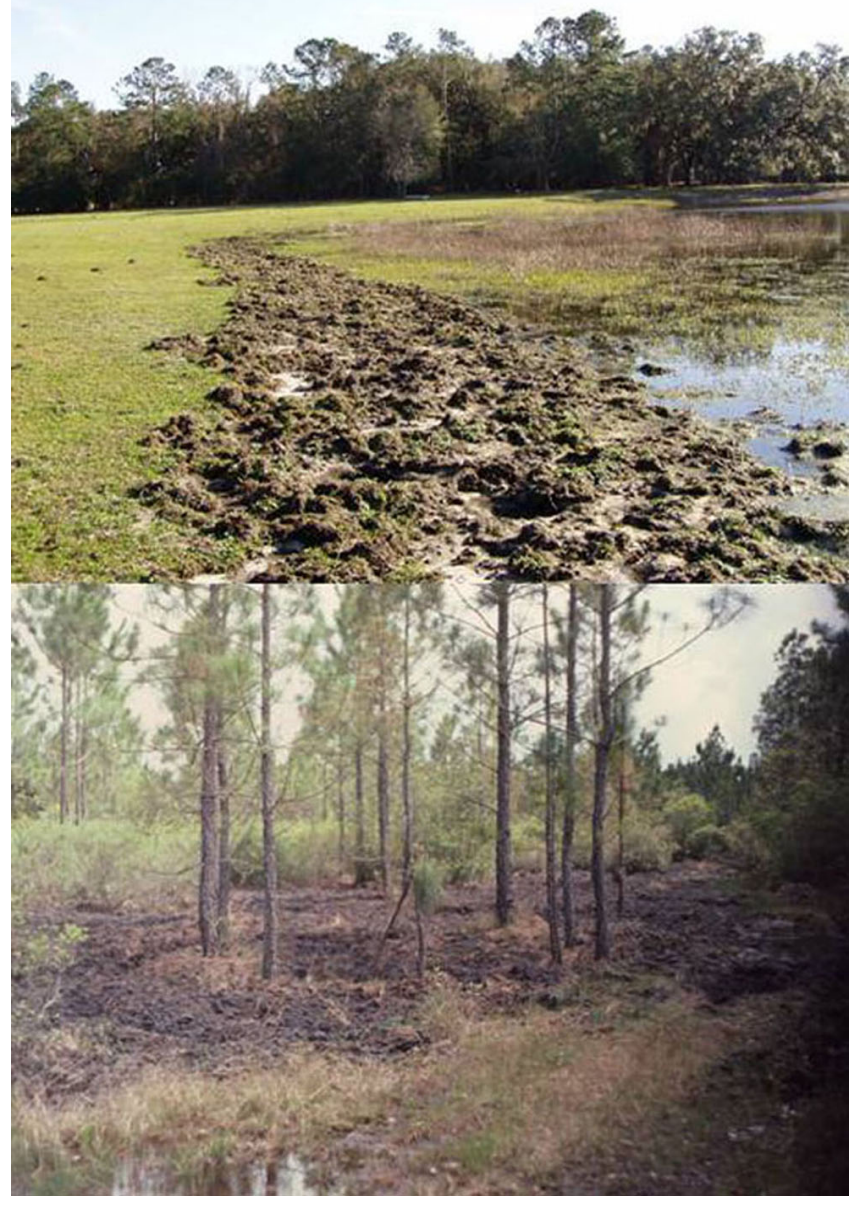

Figure 6. Rooting by wild hogs can lead to erosion and water quality problems, and the destruction of native vegetation around ponds and in the forest. Credits: Top Photo by W.M. Giuliano; Bottom Photo by W. Frankenberger.

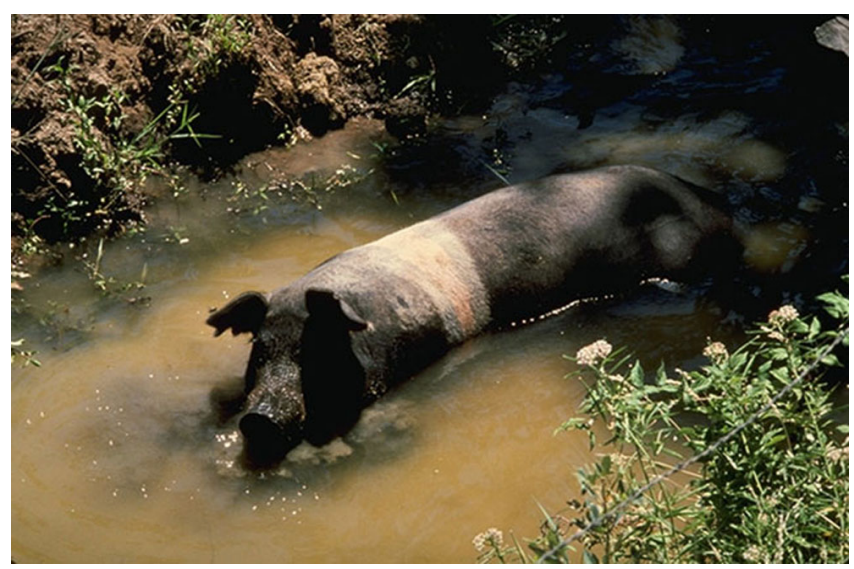

Figure 7. Wallowing by wild hogs to stay cool and reduce parasite infestation can damage the landscape. Credits: U.S. Department of Agriculture Photo.

Another area of concern is the potential for wild hogs to serve as reservoirs for many diseases and parasites that may affect native wildlife, livestock, and people. Hogs have been known to carry dozens of such pathogens, including cholera, psuedorabies, brucellosis, tuberculosis, salmonellosis, anthrax, ticks, fleas, lice, and various flukes and worms. Although not considered a serious threat to people, millions of dollars are spent each year to keep livestock safe from such problems (Figure 8).

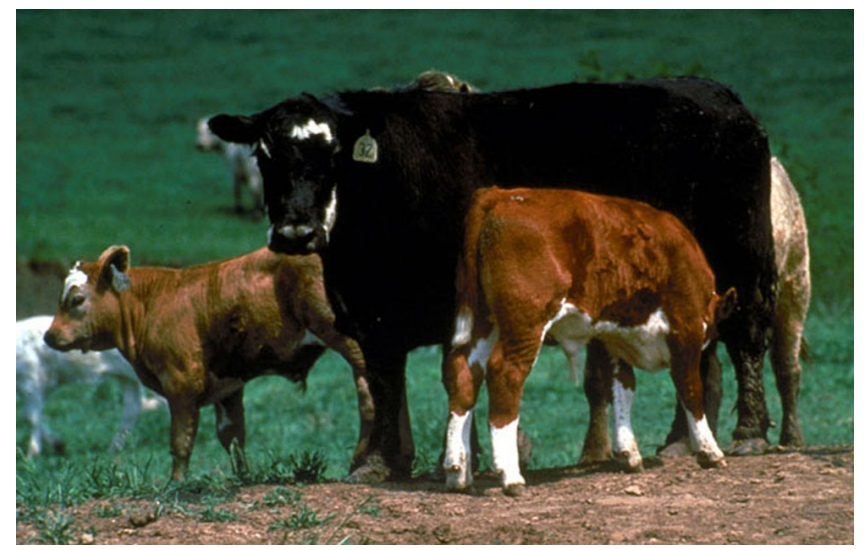

Figure 8. Wild hogs may be a resevoir for diseases and parasites that can affect people, livestock, and wildlife. Credits: U.S. Department of Agriculture/Photo by R. Stewart.

Finally, hogs can be dangerous. Although wild hogs prefer to run and escape danger, if injured, cornered, or with young they can become aggressive, move with great speed, and cause serious injury (mainly with their tusks; Figure 9).

\section{Management, Hunting, and Other Control Measures}

In most of Florida, wild hogs are considered domestic livestock and the property of the landowner where they are found. With landowner permission, there is no closed season, bag or size limit when hunting in these areas. Hunters often pay $\$ 100-\$ 2,000$ to harvest a trophy wild hog, providing an economic incentive for hog introductions and management. On public lands, both state and federal, hogs are considered legal game or simply pests and may only be taken during specific seasons and with permits.

In the past, state and private hog management included removal of hogs from public lands and other areas with sensitive ecological communities, and the introduction of animals in to other areas to maintain or establish huntable populations (Figure 10). While 


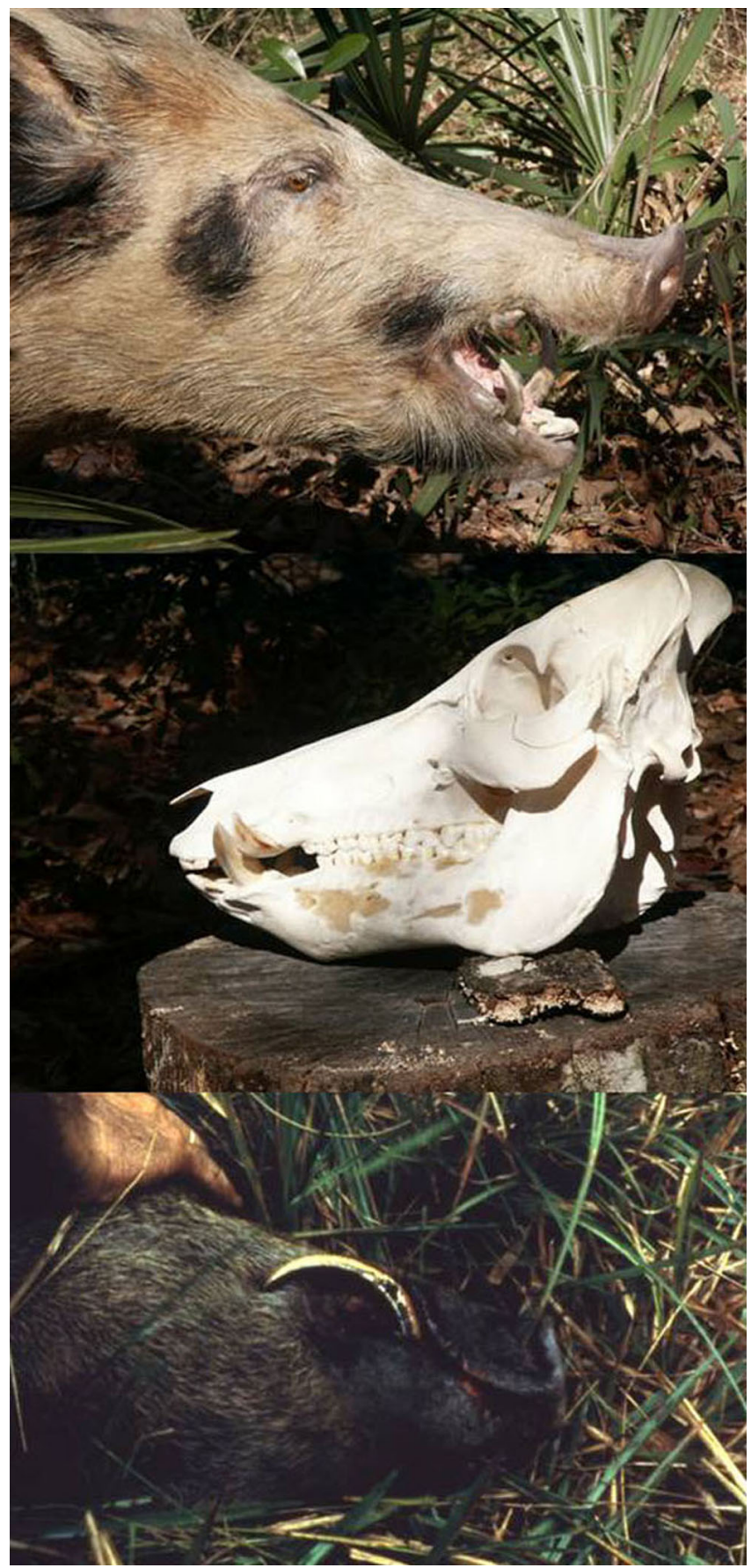

Figure 9. Wild hogs can be aggressive, and long, sharp tusks make them dangerous. Credits: Top Photos by J. Dunlap and M. Ludlow; Bottom Photo by W.

Frankenberger.

private individuals may still introduce animals in enclosed areas for hunting, most management now focuses on controlling or eradicating hog populations. Because hogs are such prolific breeders and mortality may not be able to balance hog production, further stocking of hogs in Florida will simply increase the multitude of problems associated with wild hog populations, and should be avoided. If stocking is desired on private, fenced property, only castrated males should be considered.

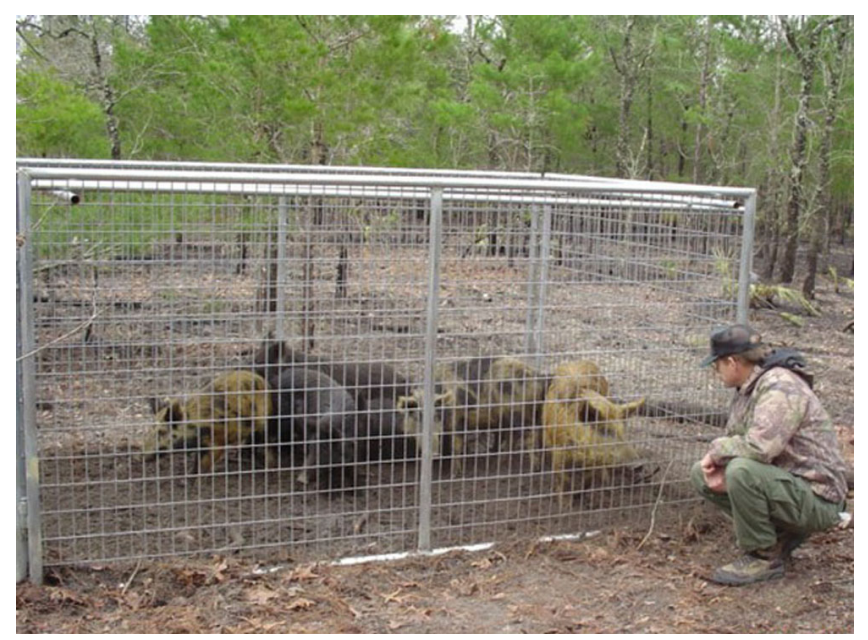

Figure 10. Trapping of wild hogs has been used to reduce populations and associated damage in some areas and supplement hog populations for harvest in others. Credits: Photo by J. Allen.

In good habitat, it is unlikely that any amount of hunting or other population control will eradicate wild hog populations, but it may be possible to limit further population expansion by using a combination of methods on a sustained basis. Wild hog control methods include hunting, various trapping methods, shooting, and exclusion. Toxicants and repellents have been suggested as a viable means of controlling or deterring hog populations. However, none are registered for use in the United States. Before undertaking any hog control measure, review local laws. The Florida Fish and Wildlife Conservation Commission (http://www.floridaconservation.org) and USDA-APHIS Wildlife Services Program (http://www.aphis.usda.gov/ws/index.html) are excellent sources of such information.

Hunting is an important control method for wild hogs because it provides recreational opportunities, is inexpensive, and can be useful at reducing numbers of adult animals. However, hogs are intelligent animals and can be challenging quarry. Many hunters consider large boars with prominent tusks to be a desirable trophy, and the lean meat is excellent fare. Typically, hogs are hunted from a stand over bait such as corn or other grains (although this may not be allowed on public lands), but can also be stalked keeping the wind in your favor. Hunting may also 
involve trained dogs to locate hogs and hold them at bay. However, dogs should be properly trained to avoid injury from hogs. Harvested animals should be field dressed as one would a deer, and gloves should be worn to reduce the possibility of disease transmission.

Trapping may be more successful at controlling hog numbers than hunting, especially when the animals are nocturnally active. While there are several types of traps (including cage, leg hold, and snare) that can be used to capture hogs, cage traps are probably most effective because they can capture multiple individuals at once. Regardless of type, traps should be well-constructed as hogs are powerful animals and easily excited when approached in a trap.

Cage or corral style live traps are the most commonly used types (Figure 11). Such traps should be located in shaded areas with large, active hog populations. This type of trap includes single- and multi-capture designs with various door/gate styles, including swinging or sliding doors and lift gates. These traps can be made from a variety of materials, however, steel fence posts with 4" x 4" welded 12 gauge (or heavier) wire fencing works well. Larger traps (often as large as $10^{\prime} \mathrm{x} 10^{\prime}$ ) will allow more hogs to be captured at once. Door frames can be made of wood or steel, with doors made of plywood (more than 3/4"), steel, or wire mesh. Doors should be at least 2' x 2', only open inward or downward (for sliding doors), and close with the use of heavy springs. Swinging doors are better than sliding doors because once an animal is caught, other animals can enter by pushing through the door, and hogs often learn to pry open sliding doors with their snout. A trip wire placed in the rear of the trap is used to trigger the door. Bait should be placed at the rear of the trap between the trip wire and door. Wire fence, attached to the walls, should be put on top (particularly if the trap has short walls) to prevent hogs from going over the top. Smaller, portable traps have also been used successfully (Figure 12). However, their size typically limits the number of captures on a single occasion to one or a very few animals. Trap construction plans can be found at sites listed in the Additional Information section at the end of this document.

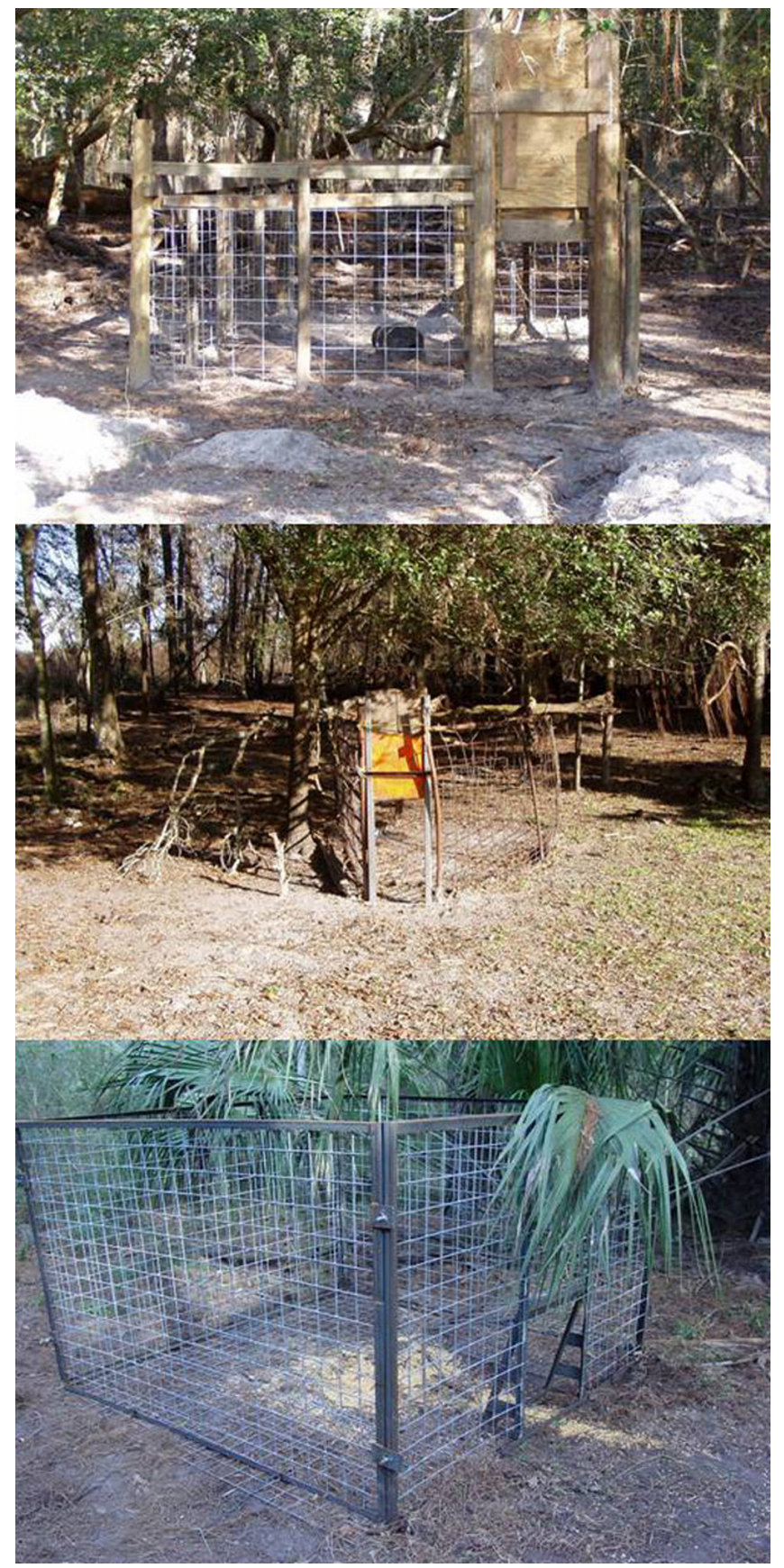

Figure 11. Baited hog traps can be an effective control method and come in various shapes and sizes. They should be sturdy enough to contain large hogs and have tall walls or a wire roof to prevent hogs from climbing or jumping out. Credits: Top Photos by W.M. Giuliano; Bottom Photo by S. Barlow.

Traps should be prebaited for several days before actual trapping begins. This involves baiting traps but locking the door open, and will allow hogs time to find the bait and grow accustomed to entering the trap, facilitating the capture of multiple animals at one time. Automatic feeders may be placed over the trap to dispense bait without introducing human 


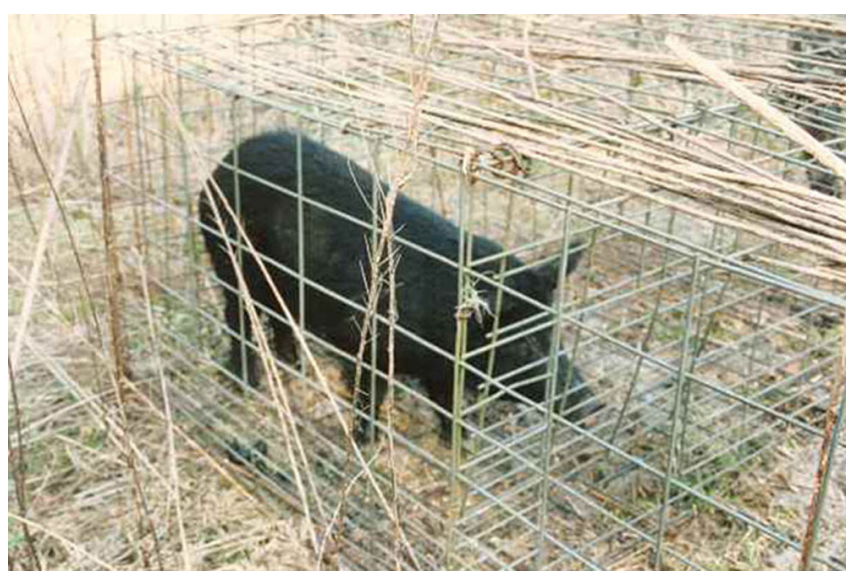

Figure 12. Small, portable traps can be effective by allowing you to move trapping locations. However, they are limited in the number of animals that can be caught on one occasion. Credits: Photo by M.S. Smith.

scent, a major deterrent to hogs entering the trap. Common baits include grains such as corn, oats, and barley (often soaked in water), vegetables, livestock feed, and carrion (dead animals). It may take several days for hogs to start coming to bait as they range over large areas. Once hogs begin visiting traps, bait must be replenished daily. Enough bait must be provided to keep hogs returning to the trap and not move on to areas with more food. At times and places with abundant natural foods such as acorns, this type of trapping may not be effective because much preferred, natural foods will reduce the attractiveness of bait to hogs. To keep livestock from eating bait and springing traps, barbed wire fencing can be used around traps (be sure hogs can get under it). In addition to bait, live decoy hogs can be placed inside traps to attract others. These hogs may be placed in a smaller pen within the trap. Such animals should be fed and watered as needed. Traps should be checked daily and from a distance (to avoid exciting the animals, which can lead to injuries and damage to traps; Figure 13).

Leg snares and steel leg hold traps (No. 3 or larger), illegal in many areas today, have been used to capture hogs. These are typically placed on active travel routes such as where hogs regularly pass under a fence, securely fastened to a heavy drag (for example, $8^{\prime}+\log$ ), tree, or fence post, and should be sturdy enough to handle a large hog. Such traps are not generally as effective as other methods because they can only capture one animal at a time. Further, such traps often capture and injure non-target

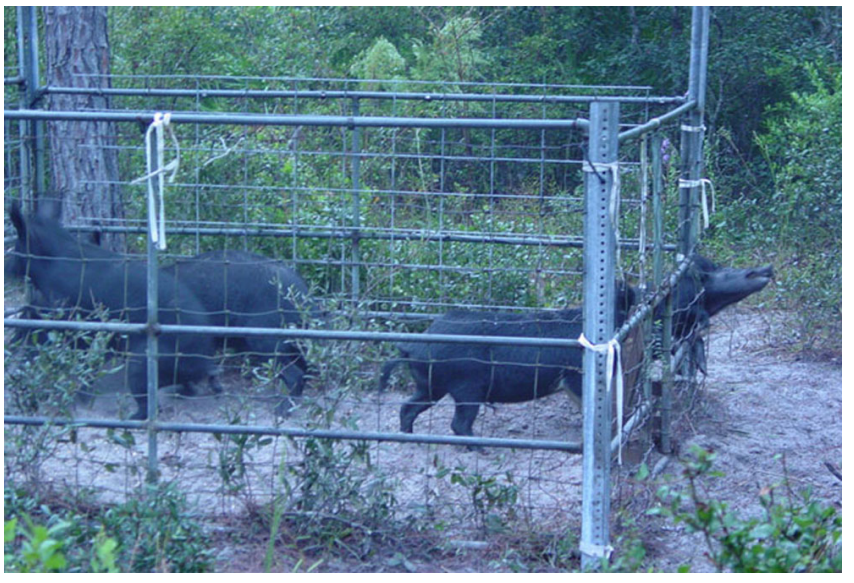

Figure 13. Traps should be checked from a distance to avoid alarming the animals, which can cause injury to the hogs and damage traps. Credits: Photo by S. Barlow.

animals, such as livestock, dogs, foxes, etc., and are not recommended. Before using such methods, individuals should check with the Florida Fish and Wildlife Conservation Commission for applicable regulations and permits. Captured hogs should be kept away from domestic animals to avoid disease transmission, euthanized as soon as possible, and remains buried or incinerated (landfills may not accept them).

Shooting at night may be an effective control measure when hunting and other human activity stimulate hogs to become nocturnal, and trapping is ineffective. Spotlights with red filters and night vision optics are valuable aids when using this method. Before using such methods, individuals should check with the Florida Fish and Wildlife Conservation Commission for applicable regulations and permits.

Excluding hogs using fencing can be an effective but expensive control option for relatively small areas such as a garden (Figure 14). However, hogs are intelligent and resourceful animals and often find ways through many types of fence. Chain link fences buried at least 12 inches under the ground with heavy supports and posts, and various types of mesh or multi-stranded electric fence provide the best results. 


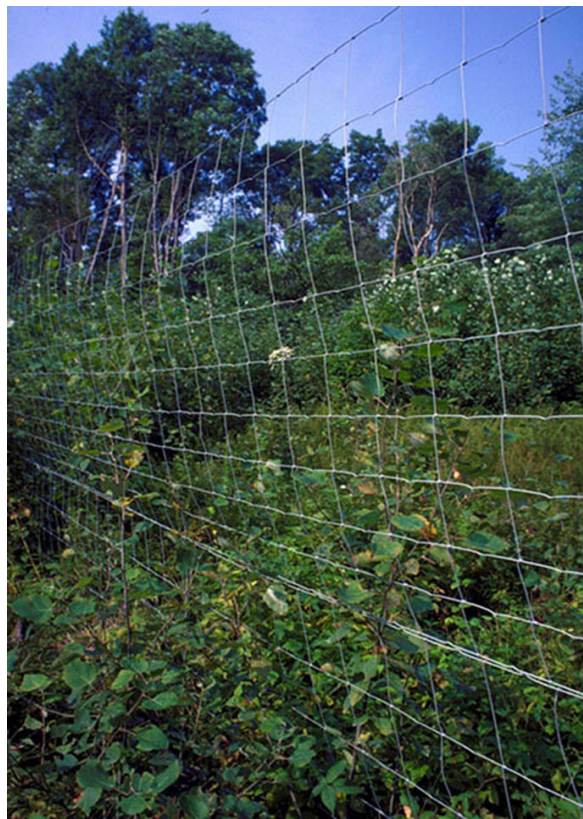

Figure 14. Fencing can be an effective method of protecting small areas from wild hog damage. Credits: U.S. Department of Agriculture/Photo by S. Roberts.

\section{Additional Information on Wild Hogs:}

http://www.wildflorida.org/critters/hog.asp

http://texnat.tamu.edu/symposia/feral/feral14.htm

http://wildlifedamage.unl.edu/handbook/

handbook/allPDF/mam_d65.pdf

http://ector-co.tamu.edu/publications/11925.pdf

http://www.noble.org/Ag/Wildlife/FeralHogs/03-

Current.htm

http://feralhog.tamu.edu/ 